\title{
Does Dietary Intake by Tehranian Adults Align with the 2005 Dietary Guidelines for Americans? Observations from the Tehran Lipid and Glucose Study
}

\author{
Parvin Mirmiran ${ }^{1,2}$, Firoozeh Hosseini-Esfahani', Mahsa Jessri', L. Kathleen Mahan ${ }^{3}$, \\ Niloofar Shiva ${ }^{4}$, and Fereidoun Azizi ${ }^{5}$

\begin{abstract}
'Obesity Research Center, Research Institute for Endocrine Sciences, Shahid Beheshti University of Medical Sciences, Tehran, Iran, ${ }^{2}$ Faculty of Nutrition Sciences and Food Technology, National Nutrition and Food Technology Research Institute, Shahid Seattle, WA, USA, ${ }^{4}$ Research Institute for Endocrine Sciences, Shahid Beheshti University of Medical Sciences, Tehran, Iran, and ${ }^{5}$ Endocrine Research Center, Research Institute for Endocrine Sciences, Shahid Beheshti University of
\end{abstract} \\ Beheshti University of Medical Sciences, Tehran, Iran, ${ }^{3}$ Department of Pediatrics, School of Medicine, University of Washington, \\ Medical Sciences, Tehran, Iran
}

\section{ABSTRACT}

The aim of this study was to compare dietary intakes by Tehranian adults with recent dietary guidelines for the Americans. The study made a cross-sectional assessment of the dietary patterns of Tehranian adults using a validated food-frequency questionnaire. It included 2,510 subjects (1,121 men and 1,389 women) aged 19-70 years. They were the participants of the third follow-up survey of the Tehran Lipid and Glucose Study (2005-2008). The dietary patterns were assessed using the latest World Health Organization (WHO)'s nutritional goals and Dietary Guidelines for the Americans Adherence Index (DGAI) 2005. The mean [standard deviation (SD)] DGAI score for this population was 8.31 (1.9). Participants in the highest quartile category of DGAI were more likely to be female, older, non-smoking, and physically active than those in the lowest quartile category $(\mathrm{p}<0.001)$. Percentage of participants meeting the DGA recommendations was low, especially for starchy vegetables (2.3\%), orange vegetables (16.2\%), lean meat (9.2\%), grains (12.0\%), and legumes (6.4\%). Over-consumption of grains was observed in almost half of the participants while approximately $20 \%$ of the subjects over-consumed milk and meat groups. Intakes of most nutrients examined were significantly associated with the DGAI 2005 score $(\mathrm{p}<0.001)$, except for vitamin E, vitamin B12, and vitamin D. The least adherence with the WHO goals was observed with n-3 PUFAs, sodium, fruit, and vegetable intakes. The results revealed that the dietary patterns of most Tehranian adults did not comply with the 2005 DGA and nutritional goals of WHO/Food and Agriculture Organization.

Key words: Adherence; Adults; Calorie intake; Diet; Guidelines; Nutrition; Iran

\section{INTRODUCTION}

The importance of maintaining a healthful diet in preventing diet-related diseases has been emphasized $(1,2)$. The Food and Agriculture Organization

Correspondence and reprint requests should be addressed to:

Dr. Parvin Mirmiran

Obesity Research Center

Research Institute for Endocrine Sciences

Shahid Beheshti University of Medical Sciences

PO Box 19395-4763,Tehran

Iran

Email: Mirmiran@endocrine.ac.ir

Fax: +982122402463
(FAO), in collaboration with the World Health Organization (WHO), has developed a series of international dietary recommendations to prevent chronic diseases and promote good health (3). Several countries also have dietary recommendations (4-7), and those from the USA have been further updated (8).

The Dietary Guidelines for the Americans Adherence Index (DGAI) 2005 is aimed at assessing the adherence of adult populations to these guidelines (9) and, compared to previous tools, it is a preferable measure of the quality of diet as it penalizes over-consumption of energy-dense foods-a shortcoming of earlier indices (10). It also assesses dis- 
cretionary calorie intakes from solid fats and added sugars and as well assesses separately the five groups of vegetables $(9,11)$. The national nutritional guidelines in Iran cover mainly the general qualitative dietary recommendations for healthful eating (12) and, hence, studies conducted on dietary habits of Iranians have used earlier versions of the food guide of the United States Department of Agriculture (USDA), showing that Iranian adults are transitioning to diets high in fat and sweets $(13,14)$ and low in meats and dairy products (15). However, updates in the DGA 2005 are more precise and informative compared to earlier versions, emphasizing the necessity of re-assessing the dietary patterns. The present study evaluated the dietary compliance of Tehranian adults with the latest WHO/FAO nutrition goals and key recommendations of the USDA food guide, using the DGAI 2005.

\section{MATERIALS AND METHODS}

\section{Study population}

The Tehran Lipid and Glucose Study (TLGS) is a community-based prospective study, performed on a sample of residents referring to three health centres in district no.13 of Tehran, the capital of Iran (16). This study, originally designed to prevent non-communicable disorders (NCDs) using a programme to promote healthy lifestyles and reduce the risk factors of NCDs (17), began in 1999, and baseline measurements are being followed every three years. Of 9,602 individuals aged 19-70 years, the participants of the Third TLGS Follow-up Survey (2005-2008), 2,881 (30\%) adults were randomly selected for dietary assessment. Men and women were proportionately distributed across five 10-year age-groups to enable generalization of results to all ages and both sexes (18). Excluded were subjects with missing data on any of the following: age, gender, physical activity, and any anthropometrical measurement $(n=97)$. Dividing the reported energy intake (rEI) by predicted energy requirement (pER), the same as estimated energy requirement (EER) resulted in ratios which, if they did not qualify for the \pm 2 standard deviation (SD) range, were considered inaccurate reports of dietary energy intake (underand over-reporting) (19). These $(n=274)$ subjects were also excluded from the study. Finally, data for 2,510 subjects-1,121 men and 1,389 women-were analyzed.

\section{Energy requirement}

The EERs of the participants were calculated, using the dietary reference intake (DRI) based on age, gender, weight, height, and physical activity levels (20). A physical activity questionnaire was used for assessing various aspects of physical activity and energy expenditure (21). Each activity category was presented to subjects as a list of examples of common activities of daily life. The participants were asked to specify time spent for sleeping and also the frequency and time spent on activities of light, moderate, hard and very hard intensity during the previous year. A metabolic equivalent (MET) value, the metabolic rate during physical activities of varying intensities as multiples of resting metabolic rate (kcal/kg/hour), was calculated to interpret the daily physical activity of each participant for the estimation of energy requirements $(22,23)$.

\section{Other measures}

Weight was measured with subjects minimally clothed, standing on digital scales (Seca, Germany) without shoes, and was recorded to the nearest 100 g. For height, subjects were measured in standing position without shoes, using a stadiometer (17). Body mass index (BMI) was calculated. Waist-circumference (WC) was measured at the umbilicus level using a non-stretch tape. Trained physicians collected additional information on age, smoking behaviour (according to the WHO guidelines), medical history, and current use of medications during face-to-face interviews $(17,24)$.

Blood glucose and blood pressure were measured by methods described earlier (17). Diabetes was diagnosed based on the latest standard protocols of the American Diabetes Association (ADA) (25) which considers fasting plasma glucose $\geq 126 \mathrm{mg} /$ $\mathrm{dL}$, two-hour plasma glucose $\geq 200 \mathrm{mg} / \mathrm{dL}$, or drug treatment for hyperglycaemia. Hypertension was diagnosed according to the criteria of the Joint $\mathrm{Na}$ tional Committee (JNC-VII) at systolic blood pressure of $\geq 140 \mathrm{mmHg}$, diastolic blood pressure of $\geq 90$ $\mathrm{mmHg}$, or drug treatment for a previous diagnosis of hypertension (26).

\section{Dietary assessment}

Trained dietitians collected dietary data using a 168-item semi-quantitative food-frequency questionnaire (FFQ) $(27,28)$. Portion sizes for each FFQ food item were specified according to the USDA portion sizes and, in some cases, household measures. The participants reported the frequency of their consumption for each food item during the previous year on a daily, weekly, or monthly basis. Since the Iranian food-composition table (FCT) (29) is incomplete and pro- 
vides data only on a few nutrients to analyze food and beverages for energy and nutrients, we used FCT of the USDA (30). For the estimation of transfat contents of foods, not included in FCT of the USDA, McCance and Widdowson's composition of foods was used (31). However, for some Iranian food items (e.g. dairy products such as kashk), not in FCT of the USDA, we used the Iranian FCT. For mixed items (e.g. pizza), nutrients were calculated based on reported basic ingredients and usual restaurant recipes; grammes of consumed food items were converted to cup- and ounce-equivalents using the 'food link pyramid database series' (32).

\section{Nutrient intake goals of WHOIFAO}

We evaluated the compliance of dietary patterns with the WHO/FAO nutrition goals. The main dietary components of the WHO/FAO goals include total fat, polyunsaturated fatty acids (PUFA), monounsaturated fatty acids (MUFA), saturated fatty acids (SFA), trans-fats, protein, carbohydrate, free sugars, n-3 and n-6 fatty acids, sodium, fruits and vegetables, total fibre, and non-starch polysaccharides (3).

\section{Dietary Guidelines for Americans Adherence Index}

This index contains calorie-specific guidelines for 10 different energy intakes based on the energy and nutrient requirements of individuals and assesses adherence to 16 key recommendations of the DGA 2005. The original DGAI has a maximum score of 20 points, 11 of which assess the 'food intake recommendations' and nine assess 'healthy choice recommendations' $(8,9)$. In our study, only 19 DGAI scores were attainable, and a subscore of healthy choice recommendations (which considers alcohol consumption) was not calculated for our population, since Iranians, based on their religious beliefs, do not drink alcoholic beverages. The maximum value for items of this index is 1.0 (consumer) and, for most items, there is a partial credit of 0.5 for persons not meeting recommendations fully but consuming over 33\% of the recommended amount (intermediate consumer). Zero point referred to those consuming $<33 \%$ of the recommended amount (non-consumer). This index also penalizes for over-consumption of energy-dense foods (i.e. meat, dairy, grains, and starchy vegetable groups) to limit the likelihood of the maximum score being obtained solely by over-consumption of energy (over-consumer) (9). An example of the DGAI 2005 used in the present study is presented for $2000 \mathrm{kcal}$ in the Appendix.
Food intake subscore: Each of the five vegetable subgroups (orange, dark green, starchy, other vegetables, and legumes) was scored separately on a weekly basis (8) (Appendix). The consumption patterns of fruits, grain, milk, meat, and various fruits and vegetables were evaluated based on the daily energy intake by the participants. Considering the recommendations of the DGAI 2005, legumes were assigned to the meat group but only for those who did not consume the meat group enough and had not met the 1.0-point criterion for this group; the intake of extra legumes was counted towards the vegetable group (8).

Discretionary energy is energy derived from solid fat and added sugar. Since the DGAI 2005 considers the solid fat component of discretionary energy in the 'saturated fat' item of the 'healthy choice recommendations', the percentage of energy from added sugar is only calculated in the 'food intake subscore' (8). Mixed food items, e.g. cookies, snacks, confectioneries, etc., which did not exactly belong to one specific food group, were considered a share of discretionary energy, and their intakes contributed to scoring 'healthy choice recommendations' (32).

\section{Healthy choice recommendations}

These recommendations, not dependent on estimated energy need, are the same for all energy levels and assess the percentage of whole grain, fibre intake, and sodium intake; five of these are related to fat and cholesterol intake, including low-fat milk and meat choices (Appendix).

\section{Statistical analysis}

All statistical analyses were performed using the SPSS software (PC version 16.0). The DGAI score was normally distributed and was divided into quartile categories. Chi-square test was performed to determine the percentage of females, low-activity participants, smokers, and subjects diagnosed with diabetes and hypertension, in two age-groups. To compare the characteristics of the participants and nutrient intakes across quartiles of the DGAI 2005 , analyses of covariance were used with adjustment for age and/or gender and energy intake.

Given that the DGAI score is a continuous measure, analysis of p-trend was used for checking whether the characteristics of subjects and their nutrient intakes were related in a monotonically-increasing or decreasing manner with the DGAI score. The linear regression coefficient was used for continuous dependent variables, and logistic regression 
coefficient was used for dichotomous dependent variables. The mean food group intakes, discretionary calories, and energy percentages as discretionary energy were analyzed by gender and two agecategories and adjusted for reported energy intake, using analysis of covariance. The percentage of consumers, non-, intermediate- and over-consumers in each component of the DGAI score was analyzed for each gender separately. Chi-square test was used for testing the differences between genders among compliers with the WHO/FAO nutritional goals. Logistic regression analysis was used for determining the risk of diabetes and hypertension across the quartile categories of discretionary calorie intakes.

\section{Ethical approval}

Informed written consent was obtained from all the subjects. The Research Council of the Research Institute for Endocrine Sciences, Shahid Beheshti University of Medical Sciences, approved the study proposal.

\section{RESULTS}

The mean (SD) age of the participants was 39.5 (13.4) years: $73.7 \%$ of men and $79.4 \%$ of women were aged $19-50$ years. The mean (SD) DGAI score was 8.31 (1.9) (range 2.5-15.0), a score shown to be associated with several characteristics of the participants (Table 1). The percentage of the female participants increased significantly in higher quartiles of the DGAI score (29.2\% vs $25.9 \%$; $=0.04$ ) while having a decreasing trend in males $(17.4 \%$ vs 30.3\%; $<<0.001$ ). Participants in the highest quartile category of the DGAI score were more likely to be older (49.1 years vs 35.3 years-males; 41.1 years vs 34.7 years-females; $\mathrm{p}<0.001$ ) than those in the lowest quartile category.

Table 2 shows the mean intakes of food group by age and sex. After adjusting for energy intake, women in both age-categories consumed significantly more fruits, total vegetables (dark-green vegetables, orange vegetables, and other vegetables), and milk compared to their male peers $(\mathrm{p}<0.001)$. Older subjects (aged 50-70 years) in both sexes consumed more fruits, total vegetables (dark-green vegetables, orange vegetables, other vegetables), and whole grains $(\mathrm{p}<0.001)$. However, their intakes from total grain, other grains, lean meat, milk, and discretionary calories were significantly lower $(\mathrm{p}<0.001)$. Women aged 19-50 years consumed significantly more discretionary calories as a share of total energy compared to their male counterparts (32.1 vs $29.8 \%, \mathrm{p}<0.001)$. About $30 \%$ of daily calories in our population were provided by discretionary energy (solid fat and added sugar) (Table 2). Participants in the higher quartile of discretionary calorie intake had higher probability of having hypertension [odds ratio $(\mathrm{OR})=1,1.33,1.96,2.16$; $\mathrm{p}<0.001]$ and diabetes $[\mathrm{OR}=1,2.01,2.62,3.00$; $\mathrm{p}=0.04]$ compared to subjects in the first quartile, after adjustments for age and gender (data are not shown).

Figure 1 shows the percentage of participants within the score categories of 'food intake subscore' of the DGAI 2005. A very low proportion of the participants met the latest USDA food guide recommendations, especially for starchy vegetables, legumes, lean meat, orange vegetables, and all grain groups. Of the subjects, $52.3 \%$ of men and $47.7 \%$ of women over-consumed grains, and $22.1 \%$ of men and $19.6 \%$ of women over-consumed the milk group, thus being categorized as over-consumers; conversely, $20.4 \%$ of men and $22.5 \%$ of women underconsumed this item.

Figure 2 shows the proportion of males and females within the score categories of 'healthy choice subscore' of the DGAI 2005, indicating that $<20 \%$ of the participants met the recommendations for sodium, low-fat milk, and meat choices. Over twothirds of the subjects failed to meet the recommendation relating to whole grain.

All nutrients examined were significantly associated with the DGAI score quartiles after adjusting for age, gender, and energy intake, except for vitamin E, B12, and D. Total fat, saturated fat, PUFA, MUFA, n-3 fatty acids, trans-fat, cholesterol, and sodium were inversely associated with the index score $(\mathrm{p}<0.001)$. Among macronutrients, there was a positive significant association between the DGAI score and total fibre, carbohydrates, and protein $(\mathrm{p}<0.001)$ (Table 3).

Table 4 shows the percentage of compliers with the WHO/FAO nutrition goals among the male and female subjects. Sex differences in adherence to these nutritional guidelines were significant in most items, with exceptions for sodium, trans fatty acids, and n-6 PUFAs. The greatest compliance with the WHO/FAO nutrition targets was for consumption of free sugars (82.2\% in males and 89.8\% in females) and cholesterol (73.9\% in males and $86.0 \%$ in females) while the least adherence was observed with n-3 PUFAs, sodium, and intake of fruits and vegetables in both sexes, with 1.0\%, $8.4 \%$ and $26.6 \%$ for males and $2.4 \%, 9.1 \%$, and $30.7 \%$ for females in each component respectively. 


\begin{tabular}{|c|c|c|c|c|c|c|c|c|c|c|c|c|c|c|c|c|}
\hline 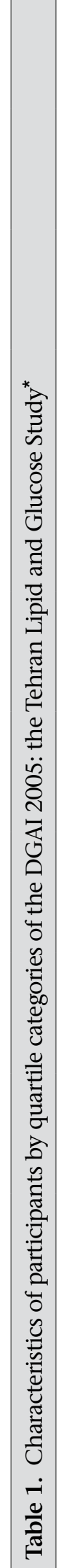 & 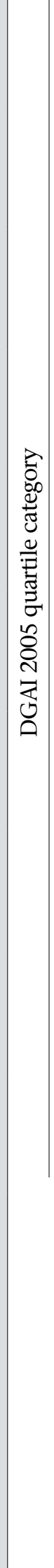 & 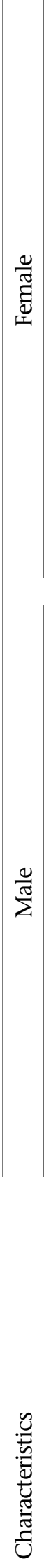 & 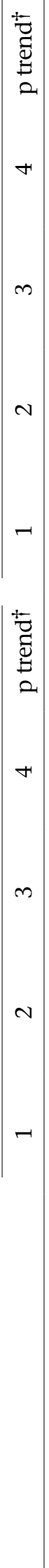 & 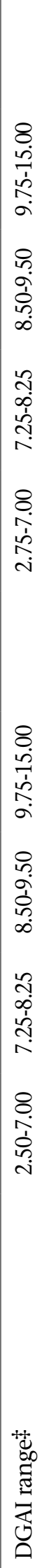 & 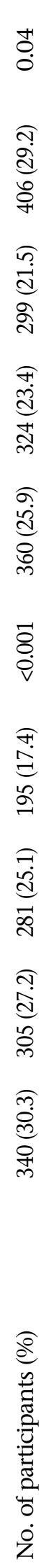 & 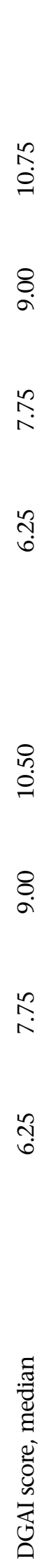 & 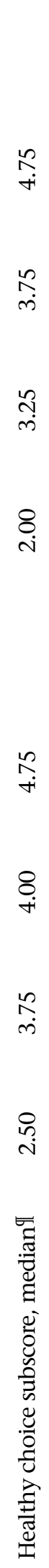 & 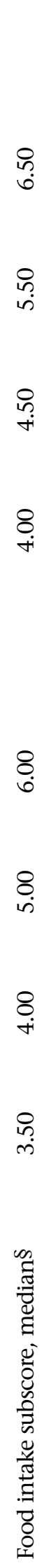 & 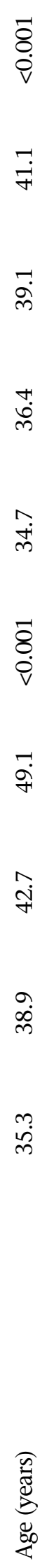 & 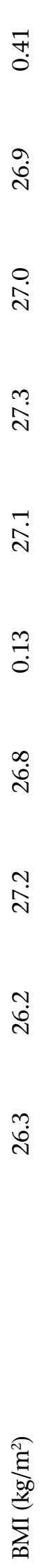 & 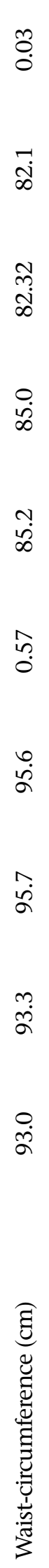 & 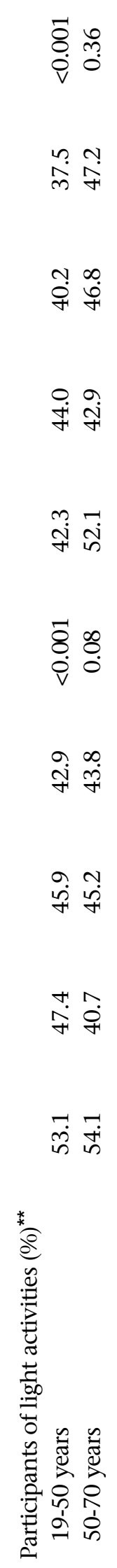 & 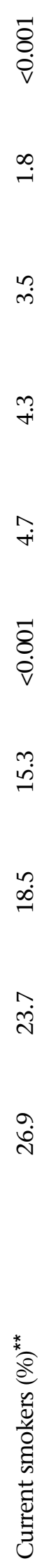 & 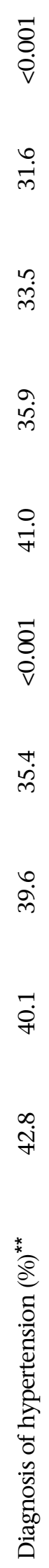 & 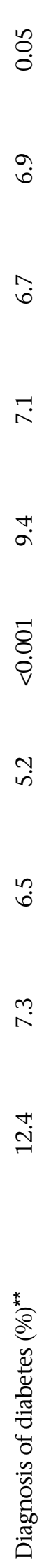 & 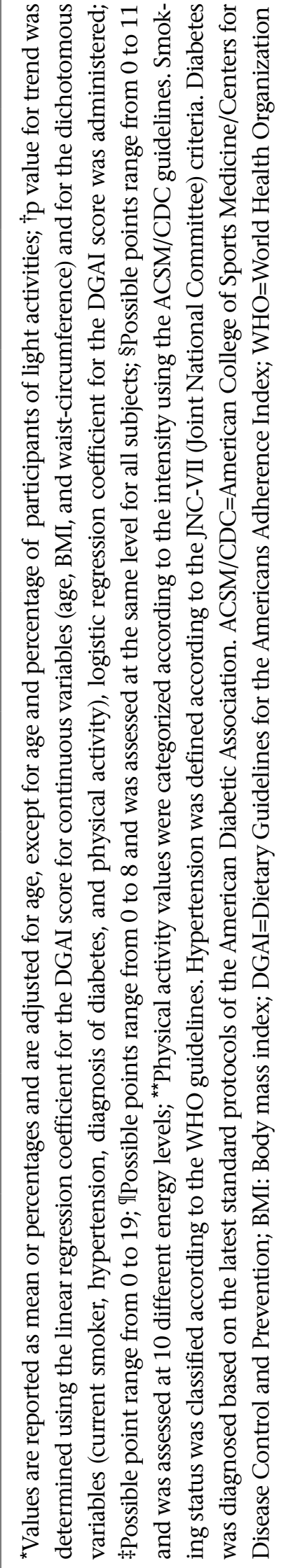 \\
\hline
\end{tabular}




\begin{tabular}{|c|c|c|c|c|}
\hline \multirow[b]{3}{*}{ Intake of food groups } & \multirow{2}{*}{\multicolumn{2}{|c|}{ Male }} & & \\
\hline & & & \multicolumn{2}{|c|}{ Female } \\
\hline & $\begin{array}{l}\text { 19-50 years } \\
(\mathrm{n}=826)\end{array}$ & $\begin{array}{l}51-70 \text { years } \\
(\mathrm{n}=295)\end{array}$ & $\begin{array}{l}\text { 19-50 years } \\
(\mathrm{n}=1,103)\end{array}$ & $\begin{array}{l}\text { 51-70 years } \\
(\mathrm{n}=286)\end{array}$ \\
\hline \multicolumn{5}{|l|}{ Fruit (cup-equi/day) } \\
\hline Unadjusted & $2.10(1.77)^{*}$ & $2.52(2.1)$ & $2.06(1.60)$ & $2.37(1.86)$ \\
\hline Adjusted $\dagger^{\dagger}$ & $1.86 \ddagger, \mathscr{I}(0.05)$ & $2.28 \ddagger(0.10)$ & $2.24 \mathbb{I}(0.04)$ & $2.62(0.10)$ \\
\hline \multicolumn{5}{|l|}{ Vegetables (cup-equi/day) } \\
\hline \multicolumn{5}{|l|}{ Unadjusted } \\
\hline Adjusted $\dagger^{\dagger}$ & $2.27(1.33)$ & $2.72(1.38)$ & $2.61(1.72)$ & $2.93(1.70)$ \\
\hline $\begin{array}{l}\text { Dark-green vegetables (cup-equi/ } \\
\text { week) }\end{array}$ & $2.05 \ddagger, \rrbracket(0.05)$ & $2.57 \ddagger(0.08)$ & $2.78 \mathbb{I}(0.04)$ & $3.09(0.08)$ \\
\hline Unadjusted & $4.5(4.1)$ & $6.02(5.18)$ & $5.27(5.17)$ & $6.57(5.23)$ \\
\hline Adjusted ${ }^{\dagger}$ & $4.05^{\ddagger}, \mathbb{I}(0.16)$ & $5.77 \ddagger(0.30)$ & $5.60 \mathbb{I}(0.14)$ & $8.30(0.30)$ \\
\hline \multicolumn{5}{|l|}{ Orange vegetables (cup-equi/week) } \\
\hline Unadjusted & $0.93(1.71)$ & $1.26(1.68)$ & $1.40(2.36)$ & $1.51(2.22)$ \\
\hline Adjusted $\dagger$ & $0.82 \ddagger, \Uparrow(0.07)$ & $1.16 \ddagger(0.11)$ & $1.49 \mathbb{I}(0.06)$ & $1.61(0.11)$ \\
\hline \multicolumn{5}{|l|}{ Legumes (cup-equi/week) } \\
\hline Unadjusted & $1.20(1.65)$ & $1.09(1.38)$ & $1.08(1.37)$ & $0.87(0.81)$ \\
\hline Adjusted $\dagger^{\dagger}$ & $1.10(0.05)$ & $1.03(0.06)$ & $1.16(0.04)$ & $0.93(0.06)$ \\
\hline \multicolumn{5}{|l|}{ Starchy vegetables (cup-equi/week) } \\
\hline Unadjusted & $1.51(1.51)$ & $1.61(1.40)$ & $1.31(1.23)$ & $1.25(1.45)$ \\
\hline Adjusted ${ }^{\dagger}$ & $1.38(0.04)$ & $1.50(0.08)$ & $1.40(0.04)$ & $1.36(0.08)$ \\
\hline \multicolumn{5}{|l|}{ Other vegetables (cup-equi/week) } \\
\hline Unadjusted & $5.60(3.80)$ & $6.53(3.80)$ & $6.64(6.01)$ & $0.44(4.88)$ \\
\hline Adjusted $\dagger^{\dagger}$ & $5.04 \div, \mathbb{I}(0.15)$ & $6.15 \ddagger(0.24)$ & 7.06I (0.13) & $8.17(0.24)$ \\
\hline \multicolumn{5}{|l|}{ Grains (oz-equi) } \\
\hline Unadjusted & $14.16(90.57)$ & $9.42(4.79)$ & $7.68(3.73)$ & $7.34(3.93)$ \\
\hline Adjusted $\dagger$ & $13.53 \ddagger, \mathscr{l}(2.1)$ & $8.77 \ddagger(0.21)$ & 8.16 प (1.8) & $8.01(0.21)$ \\
\hline \multicolumn{5}{|l|}{ Whole grains (oz-equi) } \\
\hline Unadjusted & $3.36(3.50)$ & $3.80(4.16)$ & $2.37(2.69)$ & $2.88(3.13)$ \\
\hline Adjusted $\dagger$ & $3.09 \ddagger, \mathscr{~}(0.10)$ & $3.50 \div(0.20)$ & $2.58 \mathbb{I}(0.09)$ & $3.19(0.21)$ \\
\hline \multicolumn{5}{|l|}{ Other grains (oz-equi) } \\
\hline Unadjusted & $10.44(90.54)$ & $5.26(3.47)$ & $5.58(3.05)$ & $4.82(3.07)$ \\
\hline Adjusted $\dagger$ & $10.44 \div, \mathscr{I}(2.12)$ & $5.26 \ddagger(0.17)$ & $5.58 \pi(1.82)$ & $4.82(0.17)$ \\
\hline \multicolumn{5}{|l|}{ Lean meat and beans (oz-equi) } \\
\hline Unadjusted & $3.72(2.48)$ & $3.30(2.36)$ & $2.95(1.86)$ & $2.55(1.65)$ \\
\hline Adjusted $\dagger$ & $3.36 \pi(0.06)$ & $3.03(0.01)$ & $3.22 \mathbb{I}(0.05)$ & $2.83(0.10)$ \\
\hline \multicolumn{5}{|l|}{ Milk (cup-equi) } \\
\hline Unadjusted & $2.74(1.60)$ & $2.50(1.40)$ & $2.57(1.60)$ & $2.42(1.22)$ \\
\hline Adjusted $\dagger$ & $2.50 \ddagger, \rrbracket(0.04)$ & $2.37 \ddagger(0.07)$ & $2.76 \mathbb{I}(0.04)$ & $2.56(0.07)$ \\
\hline \multicolumn{5}{|l|}{ Oils§ (g) } \\
\hline Unadjusted & $57.18(22.6)$ & $49.77(19.79)$ & $52.87(21.44)$ & $45.89(17.70)$ \\
\hline Adjusted $\dagger$ & $55.45 \ddagger(0.30)$ & $54.59 \ddagger(0.60)$ & $51.90(0.26)$ & $49.63(0.61)$ \\
\hline \multicolumn{5}{|l|}{ Discretionary calories (Kcal) } \\
\hline Unadjusted & $778(384)$ & $620(280)$ & $697(353)$ & $540(280)$ \\
\hline Adjusted $\dagger$ & 692‡,II (10.2) & $585(14.4)$ & 760II (8.8) & $576(14.7)$ \\
\hline Discretionary calories (\% energy) & $29.8 \ddagger, I(10.9)$ & $27.4(10.7)$ & 32.1 II (12.3) & $27.7(12.7)$ \\
\hline
\end{tabular}


Fig. 1. Percentage of male and female subjects within each 'healthy choice subscore category' of the Dietary Guidelines for Americans the Adherence Index 2005: the Tehran Lipid and Glucose Study

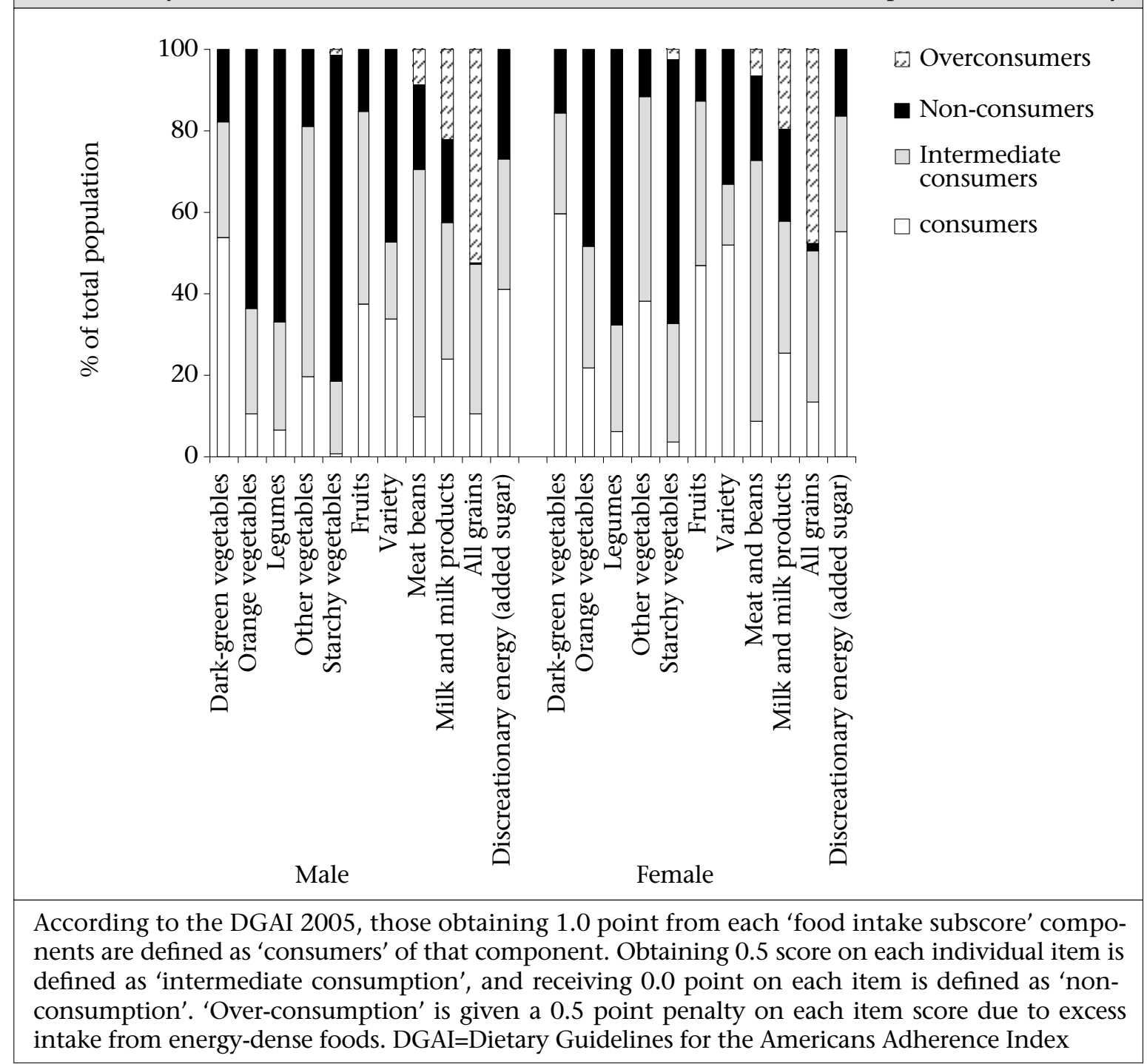

\section{DISCUSSION}

The results revealed that the dietary patterns of most Tehranian adults did not comply with the DGAI 2005 as over two-thirds of this population obtained less than 9.5 points (half the possible score) in the DGAI.

This is the first study to assess the dietary adherence of an Iranian adult population to the DGAI 2005 and the latest WHO/FAO nutritional goals. Previous studies conducted on Iranian populations used older versions of the dietary adherence tools (e.g. Healthy Eating Index-HEI) (15), highlighting the need for re-assessments. The mean DGAI score for our population was similar to that of American adults (9), taking into account the fact that the maximum DGAI score in our population was 1.0 point less than the original DGAI, following the elimination of the alcohol intake subscore.

Women, older adults, non-smokers, and active individuals (aged 19-50 years) consumed a diet more consistent with the DGAI 2005, a result similar to that of an American study using the same index (9). However, conversely, our results showed significant associations between the DGAI score and physical activity, hypertension, and diabetes. The study by Kant et al. reported a significant relationship between the DGAI and fasting insulin (11), indicating that the HEI, the recommended food score, and dietary diversity score were significantly associated with age, gender, smoking status, and physical activity. These indices were inversely related to BMI, plasma glucose, and haemoglobin AIc. The HEI was not inversely related to blood 


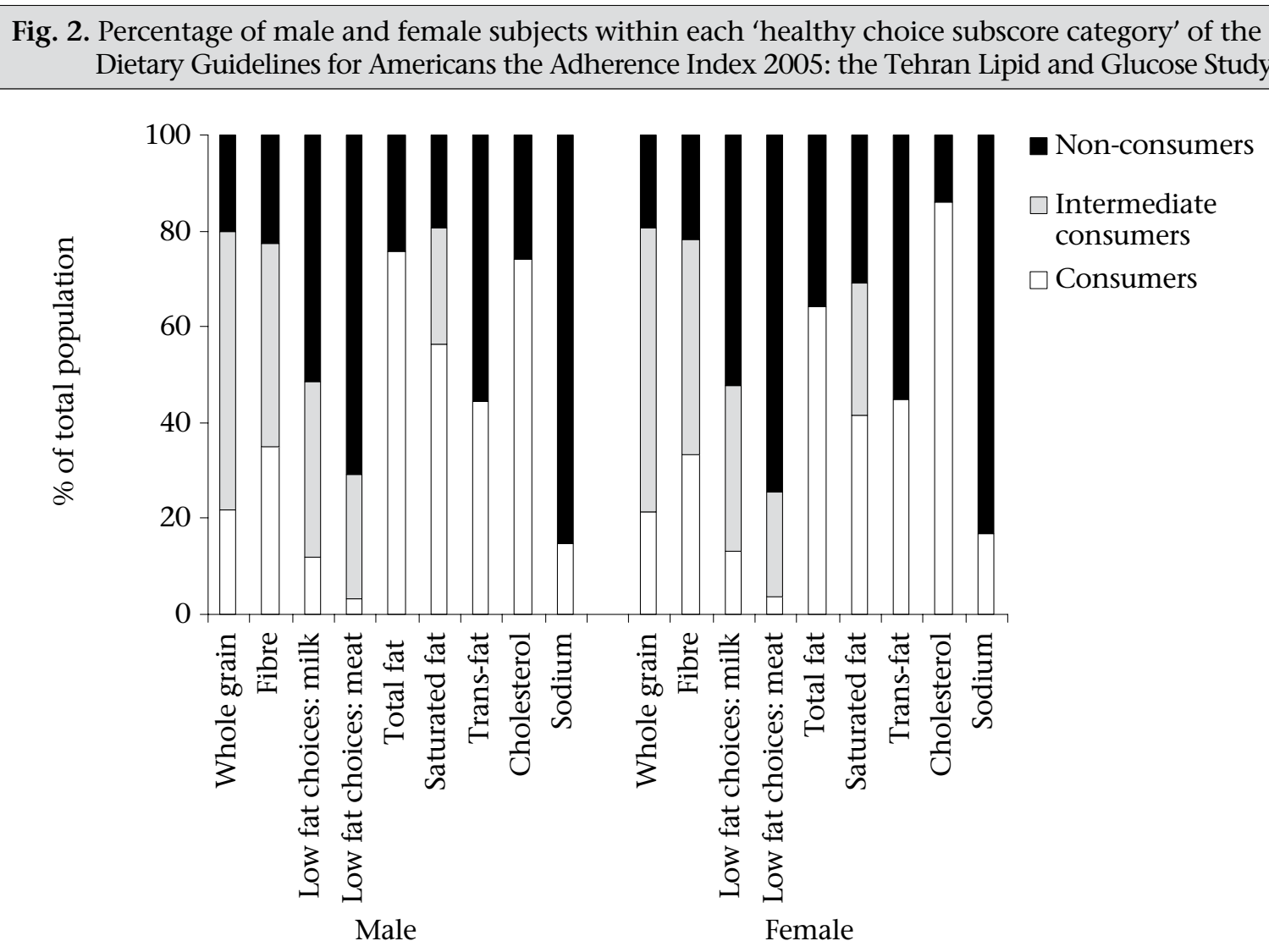

According to the DGAI 2005, each item has a maximum score of 1.0 point, except for 'low-fat milk and meat choices', with a maximum score of 0.5. Those obtaining 1.0 from each 'healthy choice subscore' component and 0.5 on low-fat milk and meat choices are defined as 'consumers'. Obtaining 0.5 points on each individual component is defined as 'intermediate consumption', and receiving 0.0 point on each item is defined as 'non-consumption'. DGAI=Dietary Guidelines for the Americans Adherence Index

pressure and serum cholesterol while two other indices showed a significant association (33).

According to the DGAI 2005, 12-20\% of total energy could be gained from discretionary calories (8). However, of concern is the finding that Tehranian adults get approximately one-third of their total energy from discretionary calories, and those in the higher quartile of discretionary calorie intake have over two times the risk of having hypertension and diabetes, similar to a previous study (34).

According to the HEI assessed earlier for our population (15), 45.4\% of the subjects obtained a 'good score' for cereals while the present study showed that only $12.2 \%$ of the Tehranian adults were 'consumers' and obtained the full score for cereal consumption, and $49.7 \%$ were categorized as 'over-consumers', explained possibly by the fact that the HEI does not consider an upper-limit for consumption of grains while the DGAI does. The prevalence of grain over-consumption is high in developing countries because grains are staple food and are, thus, over-consumed by most people due to their low cost and easy accessibility (13). Based on previous studies (15), $\leq 25 \%$ of Tehranian adults are milk-consumers, with even less over- and under-consumers, indicating a great disparity in relation to milk consumption. In the lean meat group, the number of under-consumers was higher than the number of over-consumers, showing the need for implementation of appropriate policies, since meat-group items are among the more expensive foods in Iran (13). Nutrition education, with a focus on legumes as appropriate substitutes for the meat group should be given.

Not surprisingly, individuals in the highest quartile category of DGAI were consuming more micronutrients while their intakes of macronutrients were more in alignment with recommendations compared to those in the lower quartile categories 


\begin{tabular}{|c|c|c|c|c|}
\hline \multirow{2}{*}{ Nutrient } & \multicolumn{4}{|c|}{ DGAI 2005 quartile category } \\
\hline & 1 & 2 & 3 & 4 \\
\hline DGAI range & $2.50-7.00$ & $7.25-8.25$ & $8.50-9.50$ & $9.75-15.00$ \\
\hline No. of participants & 700 & 629 & 580 & 601 \\
\hline Energy (kcal) & 2,219 & 2,194 & 2,251 & 2,374 \\
\hline Total fibre (g) & 26.2 & 28.3 & 32.0 & 32.9 \\
\hline Carbohydrate (g) & 307 & 328 & 336 & 350 \\
\hline Protein (g) & 69.8 & 71.9 & 76.8 & 85.1 \\
\hline Total fat (g) & 87.6 & 77.4 & 75.4 & 74.1 \\
\hline Saturated fat (g) & 30.8 & 27.3 & 25.0 & 23.0 \\
\hline Polyunsaturated fat (g) & 18.8 & 17.0 & 16.0 & 14.3 \\
\hline Monounsaturated fat (g) & 31.4 & 28.0 & 26.2 & 23.9 \\
\hline n-3 fatty acids (g) & 1.3 & 1.2 & 1.1 & 1.0 \\
\hline Trans-fat (g) & 4.8 & 3.9 & 3.4 & 2.4 \\
\hline Cholesterol (mg) & 258 & 223 & 220 & 203 \\
\hline Vitamin C (mg) & 98 & 114 & 147 & 190 \\
\hline Vitamin E (mg TE) & 7.9 & 7.7 & 7.8 & $8.1 \mathrm{NS}$ \\
\hline Folate $(\mu g)$ & 479 & 501 & 530 & 567 \\
\hline Vitamin B-12 ( $\mu \mathrm{g})$ & 4.2 & 4.0 & 4.1 & $4.1 \mathrm{NS}$ \\
\hline Vitamin D $(\mu g)$ & 1.92 & 1.92 & 2.00 & $2.02 \mathrm{NS}$ \\
\hline Beta-carotene $(\mu \mathrm{g})$ & 2,253 & 2,789 & 3,574 & 5,469 \\
\hline Sodium (mg) & 4,852 & 4,652 & 4,360 & 4,114 \\
\hline Potassium (mg) & 2,919 & 3,168 & 3,618 & 4,343 \\
\hline Calcium (mg) & 990 & 1,010 & 1,092 & 1,202 \\
\hline Phosphorus (mg) & 1,300 & 1,356 & 1,450 & 1,622 \\
\hline Zinc (mg) & 10.5 & 11.2 & 11.7 & 12.5 \\
\hline Magnesium (mg) & 309 & 341 & 374 & 436 \\
\hline Iron (mg) & 13.4 & 14.2 & 15.3 & 16.7 \\
\hline Vitamin A (RAE) & 460 & 467 & 537 & 715 \\
\hline \multicolumn{5}{|c|}{$\begin{array}{l}\text { *Values are adjusted for total reported energy intake, age, and gender, except for energy intake. The p } \\
\text { value for trend was calculated using the linear regression coefficient for the DGAI score for each subject. } \\
\text { p }<0.001 \text { for all nutrients, except otherwise listed; } † \text { Only micronutrients from food sources are presented. } \\
\text { DGAI=Dietary Guidelines for the Americans Adherence Index; NS=Non-significant; RAE=Retinol activ- } \\
\text { ity equivalents; TE=Tocopherol }\end{array}$} \\
\hline
\end{tabular}

of the DGAI, findings in line with those of earlier studies. A high DGAI score was positively associated with healthy lifestyle choices and optimal intakes of micro- and macro-nutrients $(9,11)$.

For most nutrition-related recommendations of the WHO/FAO, especially for n-3 PUFAs, sodium, fruits, and vegetables, we found a weak compliance, which is in agreement with those obtained using the DGAI. Compared to the nutritional goals of $\mathrm{WHO} / \mathrm{FAO}$, more compliers with total fat recommendations were found adhering to the
DGAI due to the differences in the recommendations of these tools. However, recommendations for trans-fat, SFA, and cholesterol are the same regardless of the adherence tool used. Considering both dietary adherence measures, only about half of the total population are consumers of fibre, which could, in part, be due to low consumption of whole grain, a good source of fibre. The nutritional goals of $\mathrm{WHO} / \mathrm{FAO}$ are more strict regarding sodium intake, which explains the difference in compliance when compared to the DGAI. In the case of free sugar consumption, the DGA re- 


\begin{tabular}{|c|c|c|c|c|c|}
\hline \multirow{3}{*}{ Dietary factor } & \multicolumn{5}{|c|}{$\%$ of compliers with WHO/FAO nutritional guidelines } \\
\hline & \multirow{2}{*}{ Recommendat } & \multicolumn{2}{|c|}{ Male complier: } & \multicolumn{2}{|c|}{ Female compliers } \\
\hline & & No. & $\%$ & No. & $\%$ \\
\hline Total fat (\%) & $15-30$ & 53.2 & 596 & 35.7 & 496 \\
\hline SFA (\%) & $<10$ & 56.3 & 631 & 41.6 & 578 \\
\hline PUFAs (\%) & $6-10$ & 42.6 & 478 & 49.0 & 680 \\
\hline n-6 PUFAs (\%) & $5-8$ & 43.7 & $490 \mathrm{NS}$ & 45.6 & $634 \mathrm{NS}$ \\
\hline n-3 PUFAs (\%) & $1-2$ & 1.0 & 11 & 2.4 & 33 \\
\hline Trans fatty acid (\%) & $<1$ & 44.3 & $497 \mathrm{NS}$ & 45.0 & $625 \mathrm{NS}$ \\
\hline Total carbohydrate (\%) & $55-75$ & 73.7 & 826 & 58.3 & 810 \\
\hline Free sugars (\%) & $<10$ & 82.2 & 921 & 89.8 & 1248 \\
\hline Protein $(\%)$ & $10-15$ & 72.3 & 810 & 68.2 & 947 \\
\hline Cholesterol (mg/d) & $<300$ & 73.9 & 828 & 86.0 & 1195 \\
\hline Sodium $(\mathrm{g} / \mathrm{d})$ & $<2$ & 8.4 & $94 \mathrm{NS}$ & 9.1 & $126 \mathrm{NS}$ \\
\hline Fruits and vegetables $(\mathrm{g} / \mathrm{d})$ & $\geq 400$ & 26.6 & 298 & 30.7 & 426 \\
\hline Total dietary fibre $(\mathrm{g} / \mathrm{d})$ & $>25$ & 60.2 & 675 & 47.4 & 659 \\
\hline Non-starch polysaccharides (NSP) & $>20$ & 46.1 & 517 & 62.2 & 864 \\
\hline \multicolumn{6}{|c|}{$\begin{array}{l}\text { All variables are statistically significant between sexes, except those identified as NS. *Analyses of signifi } \\
\text { cance were performed using Chi-square test; IWhole grains, fruits, and vegetables were categorized a } \\
\text { NSP; FAO=Food and Agriculture Organization; NS=Non-significant. NSP=Non-starch polysaccharides } \\
\text { PUFA=Polyunsaturated fatty acid; SFA=Saturated fatty acid; WHO=World Health Organization; }\end{array}$} \\
\hline
\end{tabular}

commendation of $\leq 5 \%$ is far more strict than that of $<10 \%$ recommended by the WHO/FAO. Thus, fewer individuals met the DGA recommendations than those who were complying with the recommendations of $\mathrm{WHO} / \mathrm{FAO}$.

\section{Limitations}

Although the strength of this study lays in assessing separately each component of the DGAI 2005 in men and women, not having a standard quantitative dietary index for the Iranian populations was a major limitation. However, the modified DGAI used in this study was assessed for face validity, and the results indicated the index associated with several health risks in an Iranian population (18). The DGAI and other American dietary indices have been previously used in different countries $(35,36)$ because dietary indices are created based on the previous knowledge of healthful diets and are applicable to different ethnic groups. However, to compensate for this limitation, we also used the dietary guidelines of $\mathrm{WHO} / \mathrm{FAO}$.

The second limitation was the use of FFQ which, despite its common use for characterizing habitual intake, is well-recognized for its weakness in the quantification of nutrient intake (37). However, being easy to complete and analyze, the FFQs are the primary source for data collection in large epi- demiologic surveys (38), being more informative of habitual intake than data on intake on a few specific days (37). The potential source of error in our use of FFQs could be from the estimation of serving sizes and lack of availability of a standardized Iranian FCT. For the validation of our FFQ, the USDA portion sizes and Iranian household measures were both used, indicating its good reliability and validity $(27,28)$. Regarding the use of FCTs to estimate nutrient intake quantitatively, the fundamental concept is that the nutrient content of specific foods is relatively constant, and variations may not be large enough to distort calculations (39). Also, estimates of long-term nutrient intakes obtained from FFQs reduce much of the error relating to sample-to-sample variation in compositions of nutrients. Moreover, using retrospective data collected within the framework of a cross-sectional study cannot accurately show compliance of, or adherence to, the dietary patterns to the DGAI 2005 recommendations. The final limitation was the inability to measure alcoholic beverage intakes as a DGAI component and, thus, having a maximum DGAI score of 19, rather than 20.

\section{Conclusions}

The results of the present study revealed that the dietary patterns of most Tehranian adults were not in accordance with the recommendations of the 
DGAI 2005 as evident from the finding that over two-thirds of this population obtained $<9.5$ points, half the possible DGAI score of 19. In both sexes, the least adherence to the nutrition targets of the WHO/FAO was for n-3 PUFAs, sodium, and intake of fruits and vegetables.

Higher compliance with these dietary guidelines was positively associated with choices of healthy lifestyle and better quality of diet in Tehranian adults. The unbalanced dietary pattern of Tehranian adults is a matter of concern, requiring prompt policy revisions and dietary interventions to promote better quality of diet. We suggest further studies to determine the association between the quality of diet, assessed by the DGAI 2005 and the health outcomes using a cohort-format study.

\section{ACKNOWLEDGEMENTS}

This work was supported by Grant No. 121 from the Research Institute for Endocrine Sciences of Shahid Beheshti University of Medical Sciences. The authors thank the participants of the Tehran Lipid and Glucose Study for their enthusiastic support and the staff of the Research Institute for Endocrine Sciences and the Tehran Lipid and Glucose Study unit. None of the authors had any personal or financial conflicts of interest.

\section{REFERENCES}

1. Rao V, Al-Weshahy A. Plant-based diets and control of lipids and coronary heart disease risk. Curr Atheroscler Re P 2008;10:478-85.

2. Carrier J. Exercise plus diet prevents type 2 diabetes (review). E vid Based Nurs 2009;12:11.

3. World Health Organization. Diet, nutrition and prevention of chronic diseases. Report of a Joint WHO/ FAO Expert Consultation. Geneva: World Health Organization, 2003:54-60. (WHO technical report series no. 916).

4. Chinese Nutrition Society. Dietary guidelines and food guide Pagoda. J Am Diet Assoc 2000;100:886-7.

5. ArancetaJ, Serra-Majem L; Working Party for the Development of Food-Based Dietary Guidelines for the Spanish Population. Dietary guidelines for the Spanish population. Public Health Nutr 2001;4:1403-8.

6. Sandström B, Lyhne N, Pedersen JI, Aro A, Thorsdóttir I, Becher W. Nordic nutrition recommendations. Scand J Nutr1996;40:161-5.

7. Koenig J, Elmadfa I. Food-based dietary guidelinesthe Austrian perspective. Br J Nutr 1999;81(Suppl 2): S31-5.

8. US Department of Agriculture. Dietary guidelines for Americans. $6^{\text {th }}$ ed. Washington, DC: US Department of Agriculture, 2005:v-ix.
9. Fogli-Cawley JJ, Dwyer JT, Saltzman E, McCullough ML, Troy LM, Jacques PF. The 2005 dietary guidelines for Americans adherence index: development and application. J Nutr 2006;136:2908-15.

10. Kennedy ET, Ohls J, Carlson S, Fleming K. The healthy eating index: design and application. J Am Diet Assoc 1995;95:1103-8.

11. Fogli-Cawley J, Dwyer J T, Saltzman E, McCullough ML, Troy LM, Meigs JB et al. The 2005 dietary guidelines for Americans and insulin resistance in the Framingham offspring cohort. Diabetes Care 2007;30:81722.

12. Safavi SM, Omidvar N, Djazayery A, Minaie M, Hooshiarrad A, Sheikoleslam R. Development of food-based dietary guideline for Iran: a preliminary report. Ann Nutr Metab 2007;51(Suppl 2):32-5.

13. Ghassemi H, Harrison G, Mohammad K, NourBalla AA. An accelerated nutrition transition in Iran. Public Health Nutr 2002;5:149-56.

14. Djazayery A, Pajooyan J. Food consumption patterns and nutritional problems in the Islamic Republic of Iran. Nutr Health 2000;14:53-61.

15. Azadbakht L, MP, Hosseini F, Azizi F. Diet quality status of most Tehranian adults needs improvement. Asia Pac J Clin Nutr 2005;14:163-8.

16. Azizi F, Rahmani M, Emami H, Mirmiran P, Hajipour $\mathrm{R}$, Madjid $\mathrm{M}$ et al. Cardiovascular risk factors in an Iranian urban population: Tehran lipid and glucose study. Soz Praventivmed 2002;47:408-26.

17. Azizi F, Ghanbarian A, Momenan AA, Hadaegh F, Mirmiran P, Hedayati P et al. Prevention of noncommunicable disease in a population in nutrition transition: Tehran lipid and glucose study phase II. Trials 2009;10:1-15.

18. Hosseini-Esfahani F, Jessri M, Mirmiran P, Bastan S, Azizi F. Adherence to dietary recommendations and risk of metabolic syndrome: Tehran Lipid and Glucose Study. Metabolism 2010;59:1833-42.

19. McCrory MA, Hajduk CL, Roberts SB. Procedures for screening out inaccurate reports of dietary energy intake. Public Health Nutr 2002;5:873-82.

20. Food and Nutrition Board. Institute of Medicine. Panel on Macronutrients. Dietary reference intake for energy, carbohydrate, fiber, fat, fatty acids, cholesterol, protein and amino acids (macronutrients). Washington, DC: National Academic Press, 2005:184-5.

21. Krishka AM, Knowler WC, Laporte RE, Drash AL, Wing RR, Blair SN et al. Development of questionnaire to examine relationship of physical activity and diabetes in Prima Indians. Diabetes Care 1999:13:40111. Reprinted in: Modifiable activity questionnaire. Med J Sports Exerc 1997;29:S73-8. 
22. Ainsworth BE, Haskell WL, Whitt MC, Irwin ML, Swartz AM, Strath SJ et al. Compendium of physical activities: an update of activity codes and MET intensities. Med Sci Sports Exerc 2000;32(9 Suppl):S498504.

23. Ainsworth BE, Haskell WL, Leon AS, Jacobs DR, Jr., Montoye HJ, Sallis JF et al. Compendium of physical activities: classification of energy costs of human physical activities. Med Sci Sports Exerc 1993;25:7180.

24. World Health Organization. Guideline for controlling and monitoring the tobacco epidemic. Geneva: World Health Organization, 1998:76-101.

25. American Diabetic Association. Clinical practice recommendations 2009. Diabetes Care 2010;33(Suppl 1):S003.

26. The seventh report of the Joint National Committee on Prevention, Detection, Evaluation, and Treatment of High Blood Pressure 2004-complete report. Bethesda, MD: National Institutes of Health, 2004:11. http://www.nhlbi.nih.gov/guidelines/hypertension/jnc7full.htm, accessed on 11 April 2009).

27. Hosseini Esfahani F, Asghari G, Mirmiran P, Azizi F. Reproducibility and relative validity of food group intake in a food frequency questionnaire developed for the Tehran lipid and glucose study. J Epidemiol 2010; 20:150-8.

28. Mirmiran P, Hosseini Esfahani F, Mehrabi Y, Hedayati M, Azizi F. Reliability and relative validity of a food frequency questionnaire for nutrients in the Tehran lipid and glucose study. Public Health Nutr 2010;13:654-62.

29. Azar M, Sarkisian E. Food composition table of Iran. Tehran: National Nutrition and Food Research Institute, Shaheed Beheshti University, 1980. 65 p.

30. Food composition table (FCT). Beltsville, MD: Food and Nutrition Information Center, US Department of Agriculture, 2009. (www.nal.usda.gov/fnic/foodcomp, accessed on 20 September 2009).
31. Robertson CE. McCance and Widdowson's The composition of foods. 6 th ed. London: Royal Society of Chemistry, 2002. 538 p.

32. Friday JE, Bowman SA. Food link pyramid database series. MyPyramid equivalents database for USDA survey food codes, 1994-2002. Beltsville, MD: Agricultural Research Service, United States Department of Agriculture, 2006. (http://www.ba.ars.usda.gov/ cnrg, accessed on 8 January 2009).

33. Kant AK, Graubard BI. A comparison of three dietary patterns indexes for predicting biomarkers of diet and disease. J Am Coll Nutr 2005;24:294-303.

34. Johnson RJ, Segal MS, Sautin Y, Nakagawa T, Feig DI, Kang DH et al. Potential role of sugar (fructose) in the epidemic of hypertension, obesity and the metabolic syndrome, diabetes, kidney disease, and cardiovascular disease. Am J Clin Nutr 2007;86:899-906.

35. Drewnowski A, Fiddler EC, Dauchet L, Galan P, Hercberg $\mathrm{S}$. Diet quality measures and cardiovascular risk factors in France: applying the healthy eating index to the SU.VI.MAX study. J Am Coll Nutr 2009;28:22-9.

36. Fisberg RM, Morimoto JM, Slater B, Barros MB, CarandinaL, Goldbaum $\mathrm{M}$ et al. Dietary quality and associated factors among adults living in the state of São Paulo, Brazil. J Am Diet Assoc 2006;106:2067-72.

37. Schatzkin A, Kipnis V, Carroll RJ. A comparison of a food frequency questionnaire with a 24-hour recall for use in an epidemiological cohort study: results from the biomarker-based observing protein and energy nutrition (OPEN) study. Int I Epidemiol 2003;32:1054-62.

38. Willet WC, editor. Nutritional epidemiology. 2nd ed. Chapter 5. Oxford: Oxford University Press, 1998:74100. (Monographs in epidemiology and biostatics series, v. 30).

39. Willet WC, editor. Nutritional epidemiology. $2^{\text {nd }}$ ed. Chapter 2. Oxford: Oxford University Press, 1998:1832. (Monographs in epidemiology and biostatics series, v. 30). 


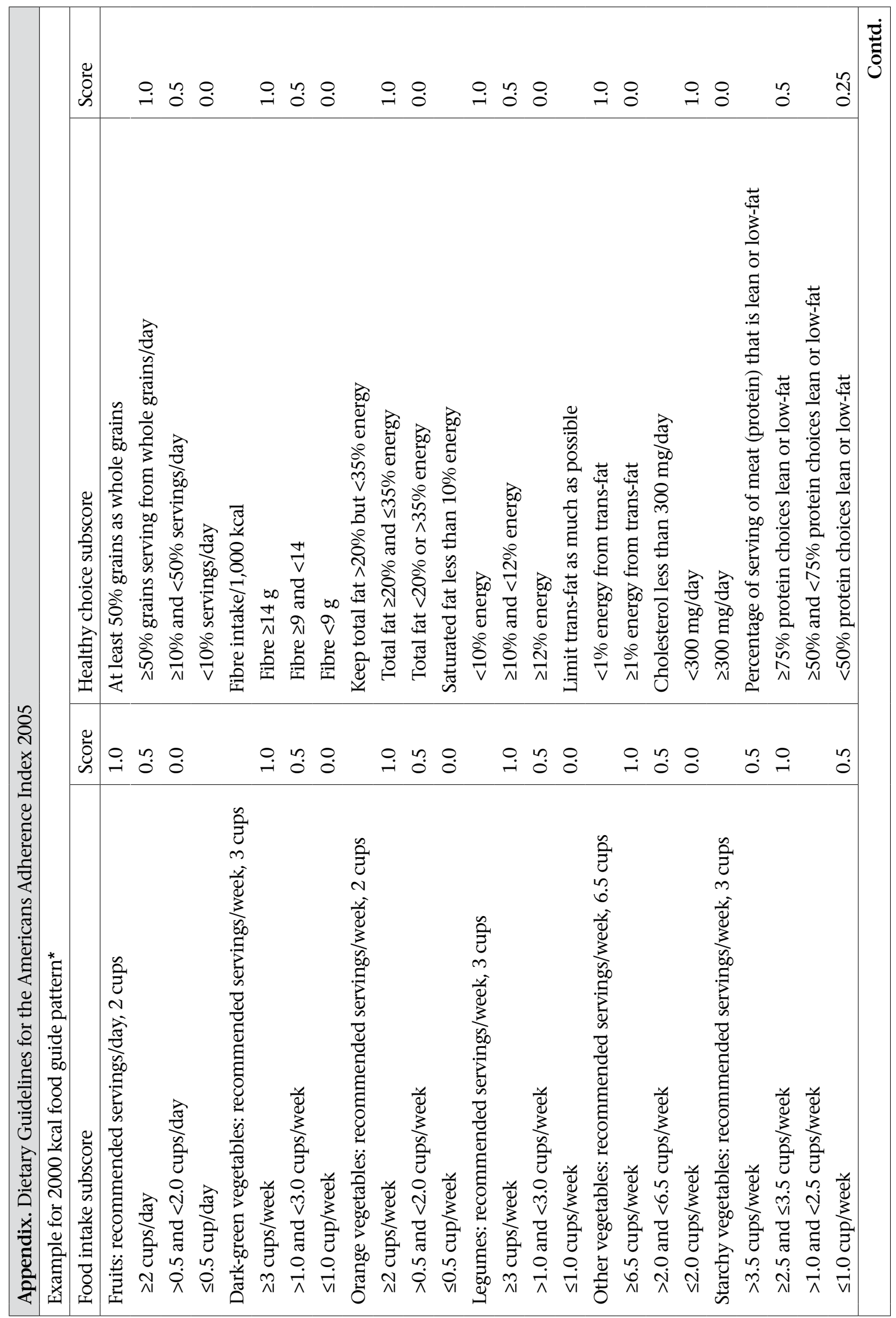




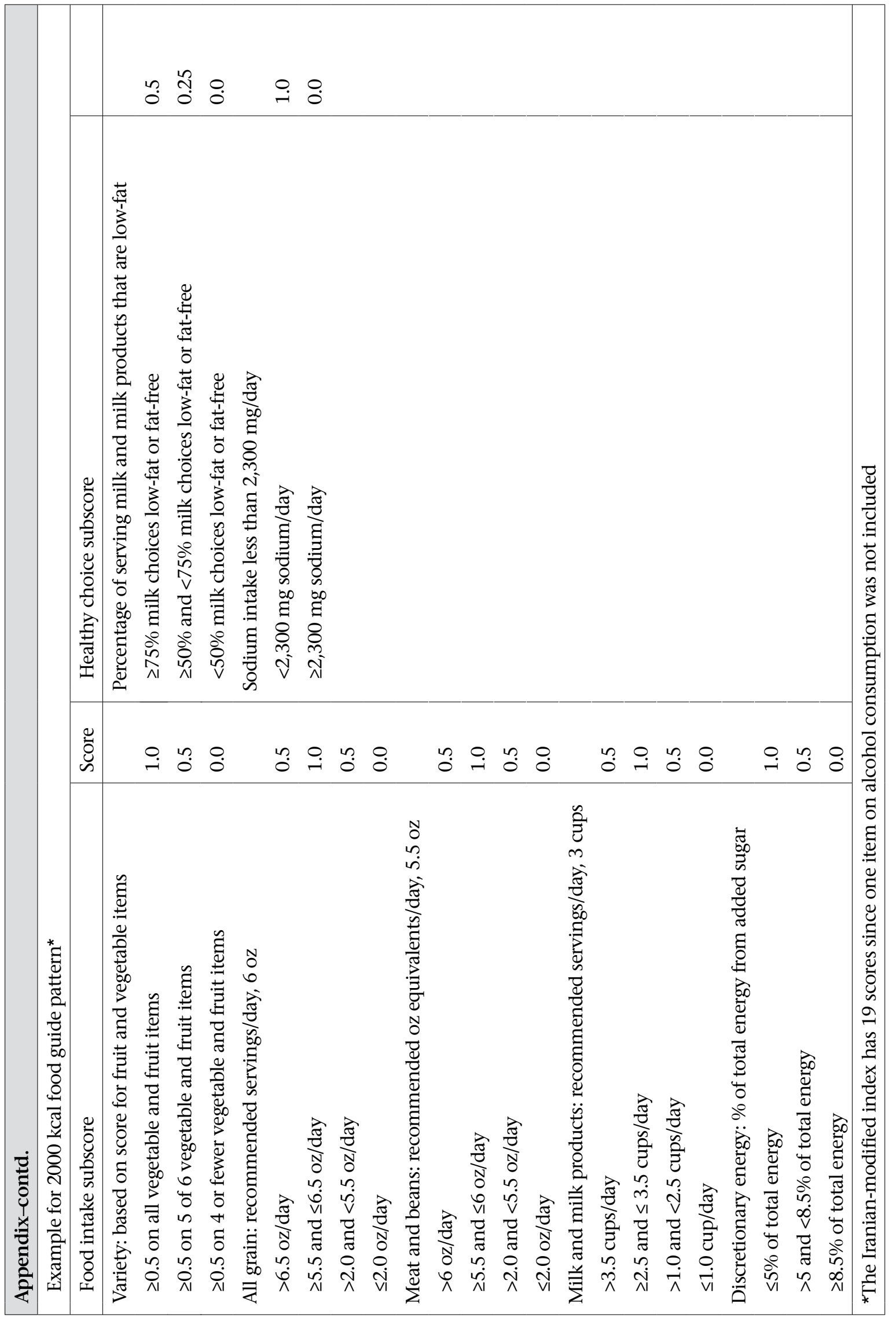

